\title{
Brief Report of Side-Scan Sonar Observations Around the Yokoniwa NTO Massif
}

\author{
Miho Asada, Kyoko Okino, Hisashi Koyama, Akira Asada, and Tamaki Ura
}

\begin{abstract}
We conducted the side-scan sonar observations of the Yokoniwa Rise, a non-transform offset massif at the southern Central Indian Ridge using the autonomous underwater vehicle AUV-r2D4 fitted with a $100 \mathrm{kHz}$ sidescan sonar system. We identified two terrain types with high backscattering signals; one terrain type exhibited typical volcanic features, while the other appeared to correspond to peridotite outcrops. The orientation of linear features identified in the survey area was highly variable, but appeared to be affected by local bathymetry. The standard deviations of the orientation and average length of these linear features were larger and smaller, respectively, than those of similar features observed along the East Pacific Rise. These observations showed that the linear features on the sonar image were likely to be flow channels or areas of the seafloor that had experienced gravitational collapse. A few small chimney-like structures were also detected.
\end{abstract}

\section{Keywords}

Peridotite outcrops $\bullet$ Side-scan sonar $•$ Yokoniwa rise

M. Asada $(\bowtie)$

Research and Development Center for Earthquake and Tsunami (CEAT), Japan Agency for Marine-Earth Science and Technology (JAMSTEC), 2-15 Natsushima, Yokosuka, Kanagawa 237-0061, Japan e-mail: asadam@jamstec.go.jp

K. Okino

Atmosphere and Ocean Research Institute (AORI), The University of Tokyo, 5-1-5 Kashiwanoha, Kashiwa, Chiba 277-8564, Japan

H. Koyama

Mitsui Engineering \& Shipbuilding Co., Ltd, 1-1, Tama 3-chome, Tamano, Okayama 706-8651, Japan

A. Asada

Institute of Industrial Science (IIS), The University of Tokyo,

4-6-1 Komaba, Meguro-ku, Tokyo 153-8505, Japan

T. Ura

Center for Socio-Robotic Synthesis, Kyusyu Institute of Technology,

2-4, Hibikino, Wakamatsu-ku, Kita Kyusyu, Fukuoka 808-0196, Japan

\subsection{Introduction}

The Yokoniwa Rise is a non-transform offset massif (NTO) situated along the southern Central Indian Ridge (CIR), immediately north of the Rodriguez Triple Junction in the Indian Ocean. It is a rectangular-shaped topographic high located at the boundary between CIR segments 1 and 2 to the north of the Kairei Hydrothermal Field (Fig. 35.1) (Okino et al., Chap. 11). A dive by the submersible Shinkai6500 in 2009 discovered a group of inactive chimneys and widely exposed peridotite outcrops on the eastern slope and top of the Yokoniwa Rise (YK09-13_leg2 cruise report available at http://www.godac.jamstec.go.jp/ darwin/cruise/yokosuka/yk09-13_leg2/e), suggesting past activity of ultramafic-hosted hydrothermal system in this area. Surveys of this area will improve our understanding of the geological control of ultramafic-hosted hydrothermal activity. Here we present the results of a sidescan sonar survey of the Yokoniwa Rise using the autonomous underwater vehicle AUVr2D4 fitted with a $100 \mathrm{kHz}$ interferometric sidescan sonar system that was conducted on cruise KH-10-06 in 2010, and geological maps produced from the obtained acoustic data set. 
Fig. 35.1 Bathymetry data of the surveyed area were obtained by the Seabeam 2120 system on the R/V Hakuho-Maru during cruise KH10-06 (Okino et al., Chap. 11). Inset is shown in Fig. 35.2a-c.

The gray areas and the two blue lines indicate coverage of sidescan sonar imagery obtained by AUV-r2D4 in 2010, and the track lines of the Shinkai6500 submersible (dives 1170 and 1176 ) in 2009 , respectively

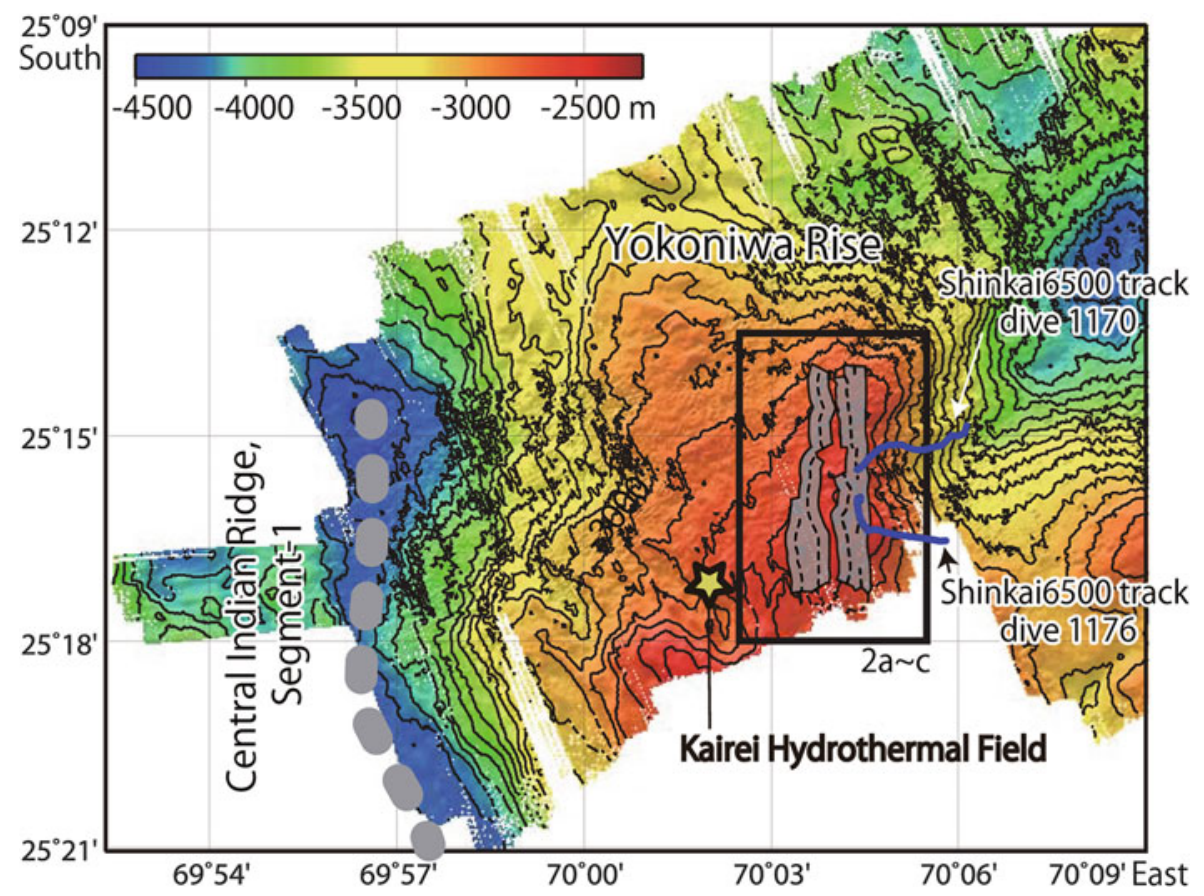

\subsection{Data Acquisition}

\subsubsection{Description of Sidescan Sonar System and Processing Procedures}

Dive 68 of AUV-r2D4 was conducted above the Yokoniwa Rise (Fig. 35.1). The r2D4 is equipped with a 100/ $500 \mathrm{kHz}$ dual frequency sidescan sonar system (Klein System). The half swath range of the sonar image is $300 \mathrm{~m}$ and an L-shaped hydrophone array is used to calculate interferometric bathymetry with high accuracy (Koyama et al. 2007).

We conducted a $19 \mathrm{~km}$ survey of the top of the Yokoniwa Rise in a north-south direction along four subparallel survey lines that covered an area of $6.3 \mathrm{~km}$ (north-south) $\times 2.4 \mathrm{~km}$ (east-west) (Fig. 35.1). The vehicle altitude during the dive was kept at $30-150 \mathrm{~m}$ above the seafloor during the survey.

We first converted the file format from that of the vendor $(* .5 \mathrm{kd})$ to a generalized XTF format, and then applied the necessary corrections to produce a mosaic image of the area using software. The resulting sonar image is shown in Fig. 35.2a. Correction and processing of the interferometric bathymetry data were conducted using proprietary software (Koyama et al. 2007). The processed interferometric bathymetry data covered $18 \%$ of the total survey area (Fig. 35.2b). The results of the $500 \mathrm{kHz}$ sonar survey data will be presented in future.

\subsubsection{Data Limitations and Considerations}

The sonar image was distorted in several places, possibly due to issues related to the stability and heading of the AUV. In addition, wedge-shaped acoustic noises, likely attributed to communication signals between the vehicle and the mother ship at 10-second intervals, were also observed (see Fig. 35.3). Since gain modification was occasionally inappropriate during data acquisition, comparisons of backscattering intensity between the port and the starboard sides require careful consideration.

\subsection{Observed Results}

As shown in Fig. 35.2, the sidescan sonar imagery revealed the presence of numerous areas with high backscattering signals. The boundaries between these areas and terrain with low backscattering were indistinct. Terrains with high backscattering signals covered $42.5 \%$ of the study area and can be classified into two types. One type was characterized by facies with volcanic features typically associated with the neo-volcanic zones of mid-ocean ridges, such as hummocky and sheet lava patterns (Smith et al. 1995; Briais et al. 2000; Sauter et al. 2002; Cann and Smith 2005; Searle et al. 2010). This type of terrain was found in the west of the observed area, on the gentle westfacing slope near the top of the Yokoniwa Rise (Fig. 35.3a). The second type of high backscattering terrain was not 


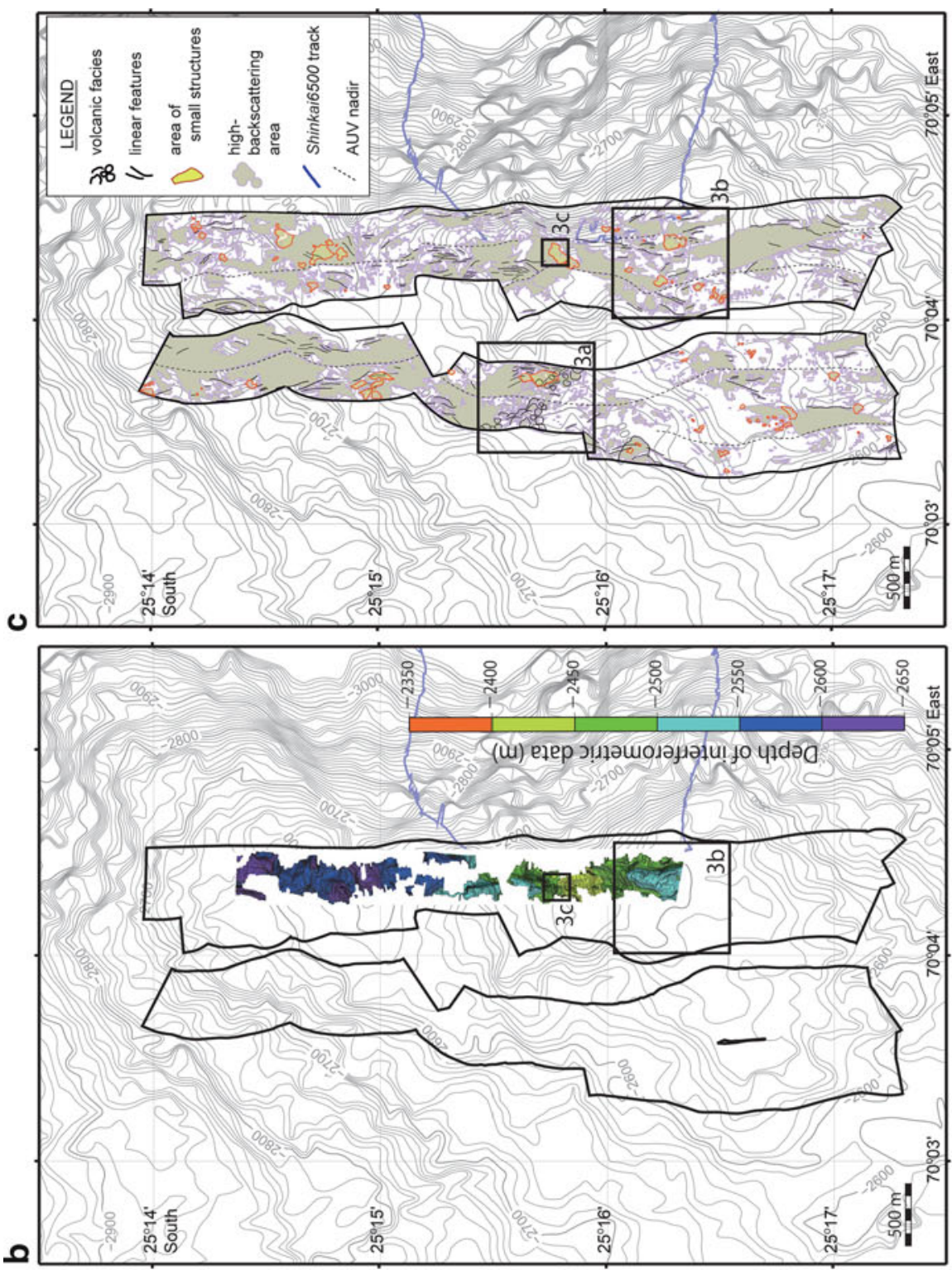

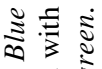

क्ष.

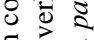

$\exists \sigma$ 政

矛

bo

ฮँ

政

공

总

品

可 을

㚜

造全些

क्षि

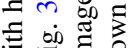

定注目

Ð $\Xi$ 흃

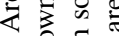

푼 월

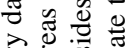

政

을

言

:

है

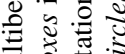

은

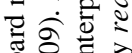

융

章过

उद्य

कू

ڤั

ప $\Xi \Xi$

के के

我穷

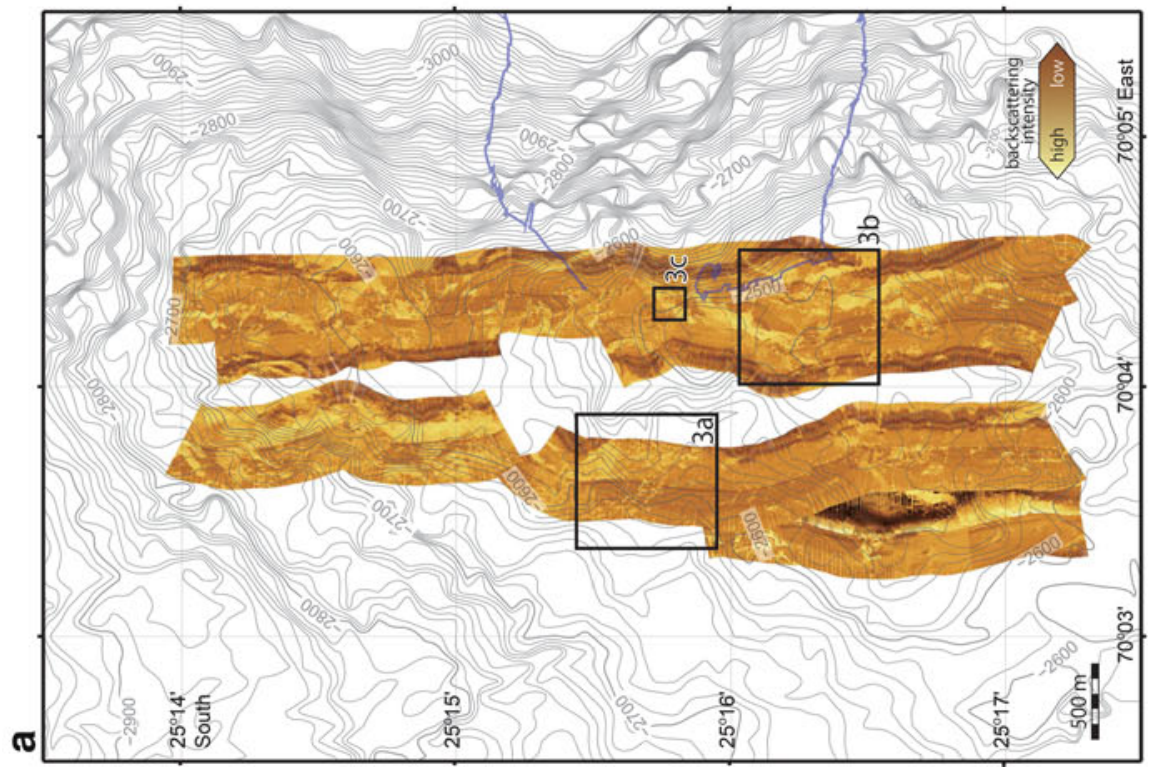

त्रิ์

Tे

过热

o

它

远

\& 50

0 ㄴํㅇ

긍

路

的苛

艺

的

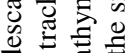

的 0

(ิ)

กุ

นิ $\Xi$ एँ

wh. 

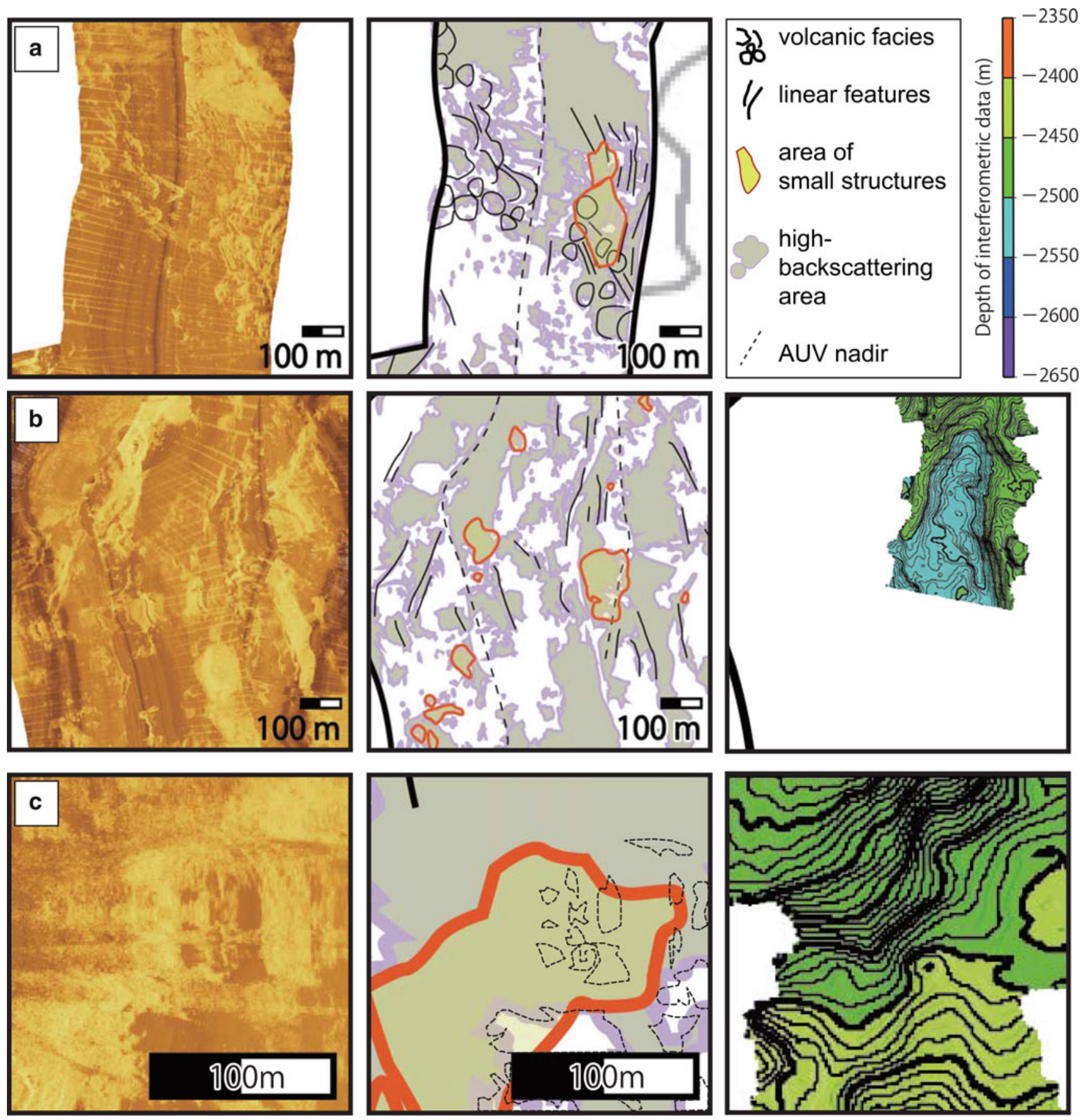

Fig. 35.3 Enlarged sidescan sonar images (left), interpretation map (center), and interferometric bathymetry data (right). The legend is the same as that used in Fig. 35.2c. The wedge-shaped lines of high backscattering across tracks are acoustic noise. (a) Volcanic features,

(b) linear features in a region of high backscattering without acoustic shadows, and (c) small, columnar, structures with acoustic shadows. Dotted circles in interpretation map indicate acoustic shadows

associated with any obvious acoustic shadows, suggesting that these areas consisted of flat seafloor (Fig. 35.3b). This type of terrain was distributed throughout the survey area, and might be indicative of flat areas with peridotite outcrops covered by either no or little sediment. Video image of peridotite outcrops covered by little sediment was recorded (dive 1176 of Shinkai6500) in this type of terrain (Fig. 35.4) (Nakamura and Onboard Scientists 2009). The indistinct boundary between the terrains with high and low backscattering signals might reflect a gradual change in the degree of sedimentation between these areas. 

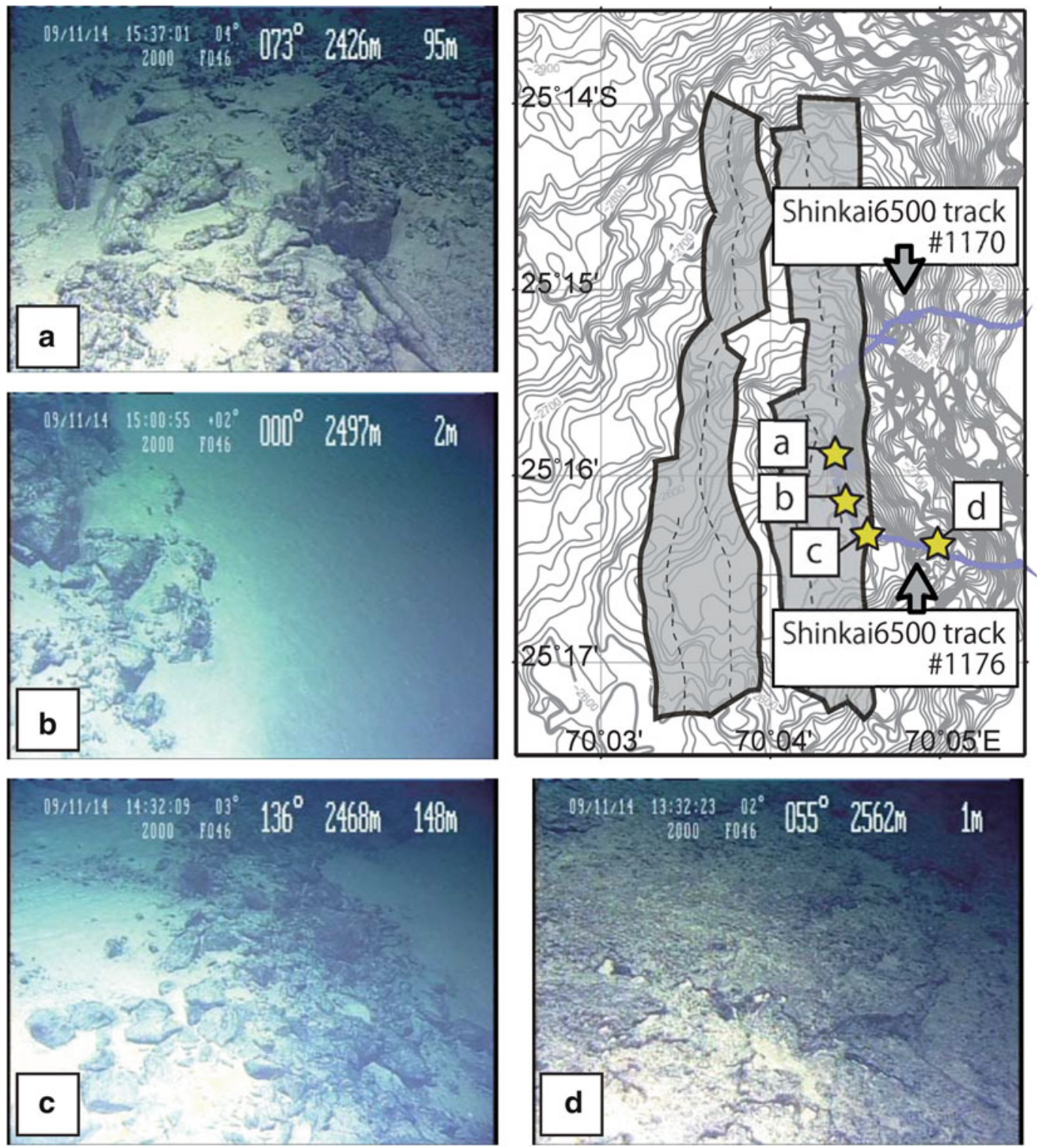

Fig. 35.4 Photographs taken by Shinkai6500 in 2009 from database of YK09-13_leg2 cuise. The location of each photo is indicated by a star on the index map (top right). Plates a-d show flat outcrops surrounded

Linear features were identified in both types of terrain in the study area (Fig. 35.3a, b). We identified a total of 216 linear features and measured their orientation and length. The orientation of these linear features was primarily parallel or orthogonal to local bathymetric variation (based on bathymetry data obtained by the Seabeam 2112 system), and not in the direction of plate motion. Average and standard deviation of the elongation direction were $\mathrm{N} 1^{\circ} \mathrm{W} \pm 20^{\circ}$. And average length of the linear features was $0.14 \mathrm{~km}$. At $20^{\circ}$, the standard deviation of the direction was larger than the value of $7.94^{\circ}$ along the East Pacific Rise (EPR) $9^{\circ} 05^{\prime}-10^{\circ} 03^{\prime} \mathrm{N}$ (based on DSL-120 data, which is $120 \mathrm{kHz}$ sidescan sonar observation by sediment at the locations indicated by the stars on the bathymetry map. The tops of the outcrops were level with the seafloor

data; Asada unpublished data). In addition, the average length of the linear features was less than that along the EPR $(0.2 \mathrm{~km})$. These observations suggest that the linear features would not attribute to be tectonic origin, but to reflect either flow channels or gravitationla collapse.

We also observed small columnar structures with acoustic shadows in terrains with high backscattering signals (Fig. 35.3c). Although these structures were interpreted to be hydrothermal chimneys, we did not observe any other indication of hydrothermal activity such as hydrothermal mounds or acoustic anomaly in water column in the observed images. 
Acknowledgements $\mathrm{We}$ thank the officers and crew of the $\mathrm{R} / \mathrm{V}$ Hakuho-Maru, members of the r2D4 technical support team, and scientists onboard cruise KH-10-06 for their assistance with the collection of the survey data. We thank the two anonymous reviewers and the editorial board of this e-book for their suggestions regarding improvements to the manuscript. This research was financially supported by the Ministry of Education, Culture, Science, and Technology (MEXT) of Japan, through a special coordination fund (Project TAIGA: Trans-crustal Advection and In situ biogeochemical processes of Global subseafloor Aquifer, FY 2008-2012).

Open Access This chapter is distributed under the terms of the Creative Commons Attribution Noncommercial License, which permits any noncommercial use, distribution, and reproduction in any medium, provided the original author(s) and source are credited.

\section{References}

Briais A, Sloan H, Parson LM, Murton BJ (2000) Accretionary process in the axial valley of the Mind-Atlantic Ridge $27^{\circ} \mathrm{N}-31^{\circ} \mathrm{N}$ from TOBI side-scan sonar images. Mar Geophys Res 21:87-119

Cann JR, Smith DK (2005) Evolution of volcanism and faulting in a segment of the Mid-Atlantic Ridge at $25^{\circ} \mathrm{N}$. Geochem Geophys Geosyst 6:Q09008. doi:10.1029/2005GC000954
Koyama H, Asada A, Ura T, Han J, Obata T, Nagahashi K (2007) Bathymetric survey at hydrothermal site by L-array Interferometric sonar mounted on AUV-r2D4. In: Underwater technology and workshop on scientific use of submarine cables and related technologies, pp 156-161, 10.1109/UT.2007.370845, 17-20 April, Tokyo

Nakamura K, Onboard Scientists (2009) YK09-13_leg2 cruise report. http://www.godac.jamstec.go.jp/darwin/cruise/yokosuka/yk09-13_ $\operatorname{leg} 2 / \mathrm{e}$

Sauter D, Parson L, Mendel V, Rommevaux-Jestin C, Gomez O, Briais A, Mevel C, Tamaki K, The FUJI Scientific Team (2002) TOBI sidescan sonar imagery of the very slow-spreading Southwest Indian Ridge: evidence for along-axis magma distribution. Earth Planet Sci Lett 199:81-95

Searle RC, Murton BJ, Achenbach K, LeBas T, Tivey M, Yeo I, Cormier MH, Carlut J, Ferreira P, Mallows C, Morris K, Schroth N, van Calsteren P, Waters C (2010) Structure and development of an axial volcanic ridge: Mid-Atlantic Ridge, 45 degrees N. Earth Planet Sci Lett 299:228-241

Smith DK, Cann J, Dougherty ME, Lin J, Spencer S, Macleod C, Keeton J, Mcallister E, Brooks B, Pascoe R, Robertson W (1995) Mid-Atlantic Ridge volcanism from deep-towed side-scan sonar images, $25^{\circ}-29^{\circ} \mathrm{N}$. J Volcano Geotherm Res 67:233-262 